\title{
Thoughts on Developing Thematic Educational Activities at Different Levels in Vocational Colleges
}

\author{
Yan Han \\ Jiangsu province xuzhou technician institute \\ Xuzhou, Jiangsu 221151, China \\ 1030638329@qq.com
}

\begin{abstract}
The goal of educating people in vocational colleges is to cultivate applied talents with certain cultural level, professional knowledge and skills, and comprehensive accomplishment in order to meet the objective needs of individual employment, promote the development of social productivity, and speed up the adjustment and transformation of the national industrial structure. For this reason, it has become a consensus that vocational colleges at all levels should enhance students' knowledge and skills education and strengthen the students' comprehensive quality. Based on a brief analysis of the current situation, this paper puts forward the idea of hierarchical activities and bi-directional evaluation mechanism.
\end{abstract}

Keywords-Vocational college; Hierarchy; Educational activity

\section{INTRODUCTION}

Over the years, vocational colleges have attached great importance to the cultivation of students' comprehensive quality [1]. The school has set two major functional departments-the student affairs office and the Youth League Committee to guide the ideological and behavior education of the whole school, and has achieved fruitful results. In the specific work process, the activities of students in secondary colleges are mainly planned by the two major functional departments, supplemented by teaching activities set up by the academic affairs office. When they are settled down to the secondary college students, the students will not only be too busy, there are also overlaps in time and space.Moreover, there is no connection between these thematic activities [2]. The quantitative change will not form an effective qualitative change and it will even produce fatigue and become formalistic thereby losing the meaning of the activity. To better achieve effective goals, the author thinks as follows:

\section{SET UP STUDENT-ORIENTED GUIDING IDEOLOGY AND THE SENSE OF CLEAR DIVISION OF LABOR}

The school should adhere to the idea that student is the main body, teacher plays the leading role and the learning management department takes the responsibility of guidance [3].Before carrying out the work, the functional institution should first organize the relevant personnel to formulate a comprehensive training program for quality education. In the course of carrying out the work, the college should deploy the theme of education in this term or school year and make a general plan. On this basis, the school management institutions of the secondary college should carry out the rough lines of thought, and combine the professional features of their own colleges and the main body of the activities - the students' growing rules and abilities, and formulate an elaborated activity plan, so as to highlight the actual results and point to the goal of educating people [4].

\section{CARRY OUT HIERARCHICAL THEME EDUCATION ACTIVITIES}

As is known to all, because of the uneven learning foundation of the students in the class, it is often adopted to set different teaching goals and to lay particular emphasis on the content of teaching in different levels. Because of the differences in the growth environment, cultural background and the college major of the students, the problems and needs of students in different grades will be different. Only by following the development law of the students' growth, making scientific and systematic planning and promoting in order can we improve the pertinence, feasibility and effectiveness of education in practice.

\section{A. Grade level}

That is, setting up activities according to the growth pattern of the students from the age of entry to graduation. Lower grade students have pessimism because of the failure of the college entrance examination and poor learning ability accumulated for many years, and lack of sufficient learning enthusiasm. Students have curiosity about the new school's teaching model and the unfamiliar environment of the campus. They also have many bad habits developed before entering the school. Their thematic activities should focus on "formation" education-First of all, carrying out belief education to help students establish the confidence that "professional talents are easier to find jobs" and stimulate their professional learning motivation. Carrying out psychological quality education and series of mental health education activities to enhance students' sense of belonging and allow them to accept the learning status with a calm and happy attitude. Secondly, carry out activities such as the student knowledge competition, the internal affairs evaluation, the appearance instrument, the civilized dining evaluation and various civilized behavior development activities. Third, organizing professional meetings to help new students have a comprehensive understanding of the subjects they will study and a clear direction for the goals and tasks 
when they come to the schools. Fourth, organize new recruiting meetings to enrich students' leisure life and demonstrate their personality and specialty; And hold the thematic class meeting, multi-tasking, tug-of-war competitions, hot wheels, relay races and other activities to promote mutual understanding, enhance friendship among students and strengthen group cohesiveness. Fifth, strengthen legal education, correct bad learning and living habits, eliminate vicious events, and promote compliance with rules and regulations. In order to promote the improvement of the students' professional knowledge and skills, the middle grade students should focus on the cultivating activities such as traditional culture education, the theme of the craftsman spirit, gratitude education, life education, aesthetic education, collectivism education, training of the student cadres' ability, the group knowledge competition, the ball league tournament and join hands with the educational departments of the school to carry out the educational activities based on professional education. And on this basis, organize students to participate in the social practice activities and encourage students to obtain the corresponding qualification certificates. For senior students, they should first focus on activities with professional characteristics and better social cohesion such as "talent show, legal lecture, rights debate, corporate culture experience and resume design competition". Secondly, the alumni cultural festival can be held. With the help of the returning of the alumni, the school can carry out the "Words of Employment and Life" activity to help students understand the development and professional requirements of the industry correctly. Third, organize employment and entrepreneurship seminars and a series of publicity activities to help students establish a correct outlook on life and employment and improve their employability. Fourth, carry out employment psychological counseling to relieve the psychological pressure of college students.

\section{B. Institutional level}

1) Arrange and organize school-level activities in an allround way and conduct comprehensive education in all aspects.

For national guidelines and policies, such as spiritual education, legal education, moral lecture, craftsmanship, safety education, human rights debate, sports league, manner and behavior, civilization cultivation, thanksgiving education, life education, honest education, environment protection education, etc. General education can be planned and deployed from the school level, and all students should be educated according to certain plans, so as to enhance comprehensive education.

2) Secondary colleges combine education with professional characteristics

Professional teaching and student management are not two non-intersecting parallel lines, but are closely connected and mutually reinforcing. They have the same goal and both point to the goal of educating students. In addition to the general education required by the functional departments, the student activities should give the secondary colleges rights of choices and highlight professional characteristics. On the one hand, it is to enhance professional charm and stimulate interest in learning through "promoting special education to promote learning". For example, preschool education majors can launch series of activities such as dancing competition, good voices, concerts, manual salons, "I'll be a teacher" simulation class, and "three words and one sentence"; The Culinary Specialty can launch Chinese-Western style pasta competition, I am a chef, tasting bartender and other activities; Information technology direction can host my Internet+, programming age, animation world; Architectural decoration professional can hold exhibitions, "I am a designer" and other thematic activities. On the other hand, the decentralization of the right to independent design of activities is more conducive to the "cute women can do with rice", thereby improving the quality of activities and even forming brand activities. Whether it is the exchange visits between brother universities, or all kinds of competitions at the municipal level or above, they can be selected according to the theme so as to get twofold results with half the efforts.

3) Move down the theme activity right and carry out independent personality education. Students are the objects of education and the main body of specific activities.

Fully respecting the students' subjective consciousness, fully establishing the students' main body position and giving full play to the student's main role can not be diluted. For example, let students work as teacher assistants, principal assistants and transfer rights to students to actively plan class activities, professional activities or department activities to promote their scientific and democratic participation in school affairs management and activity design. This is also an innovative attempt. It will not only cultivate students' sense of ownership, but also promote their work and management skills. This in itself is an important part of vocational education.

\section{PAY ATTENTION TO THE CONSTRUCTION OF STUDENT ORGANIZATIONS}

Student community is an important carrier of campus culture construction. It is not only the leader of the students' second classroom, but a voluntary and regulated mass student organization in order to meet the demands of students with common interests to achieve common wishes. Vocational colleges have mostly solved the problem of students' associations from missing to plentiful. They have taken an important step in the construction of mass organizations, but there are also some areas that need improvement: On the one hand, the composition of student clubs can be across grades, across classes, or even across colleges; Teaching plans of club lessons can be provided in the form of an activity scheme, highlighting the purpose of the event, the idea of activities, and the analysis of the effects of activities. The evaluation of club lessons can be carried out regularly or irregularly by specialized personnel. It can even promote the development of societies in various forms such as community teacher training, model observation courses, collective lesson preparation, community event tours, and community club competitions.

\section{A. Improve the cohesiveness of the community}

It is often said that motivation determines behavior, because of the spontaneity and looseness of the student association, it is difficult to use the constitution and the specific system to restrain the behavior of the members of the community. Only when the goals are the same can the cohesion 
of the community be improved. At the same time, the leadership style of the instructors and the student cadres will also have an impact on the cohesiveness of the community. Only the "democratic" leadership mode can guarantee the internal cohesion of the community. Finally, students' associations can increase their influence on campus and even out of school through colorful activities. By carrying out and accomplishing all kinds of community activities to meet their sense of social identity, it will naturally raise the reputation of the community, which will greatly improve the sense of honor of the members. Therefore, the more honor the community gains, the more cohesive force it can enhance.

\section{B. Improve the executive ability of students' association cadres}

The cadre of a community is the leading figure of it and the one that the members of the community follow. His talents, abilities and qualities are the important factors to determine whether the development of a community has a future. First of all, when selecting or appointing student association cadres, we must fully promote the spirit of democracy and elect the cadres who are fully recognized and trusted by community members. Secondly, schools should organize regular training of student leaders, especially the special training of working skills closely related to management. For example, how to improve executive power and how to improve writing. Through the training of student cadres, the overall quality of individuals and even the whole community can be improved and the healthy development of student organizations can be promoted. Third, improve the evaluation system for student community cadres and implement the responsibilities clearly and concretely to every association official. Regularly assess their work goals and whether the activity organization achieves the desired results. At the same time, urge student cadres to selfsummarize and submit regular work reports to objectively evaluate the overall capabilities of student cadres. The assessment results can be linked to the student's vital interest rewards, and further promote the self promotion of student cadres. Finally, strengthen the communication between student cadres from different societies, community cadres and administrators to ensure the cross-flow of information.

\section{Strengthen the guiding role of the instructors}

First, fully examine the professionalism, work experience and management ability of the candidate instructors. Second, seriously consider whether the candidate instructors have enough interest, enthusiasm, patience and confidence in leading the growth and development of student communities and whether they are willing to invest enough time and energy in building the community. Third, fully consider the candidate's professional orientation and the matching degree of the community type and try to hire teachers or senior experts who are related to the professional type of the club activity because the teacher with strong association with the nature of the community can fully meet his professional abilities and lead the community to grow steadily and healthily. Finally, strengthen the training of community guidance teachers and attach importance to the incentive system construction of teachers' team.

\section{Provide the basic guarantee for the development of the communities}

The sustainable development of student associations is usually restricted by problems such as lack of basic activities and shortage of resources. First of all, the rational planning of school infrastructure construction and regular maintenance of existing facilities can provide material guarantee for the development of student associations. Secondly, from the perspective of schools, efforts should be made to provide necessary funds for student associations. At the same time, through the system of the declaration of funds activities, we should strengthen the support for the good activities and appropriately reduce the funds for the bad activities to ensure the rational distribution of the limited funds. Third, from the perspective of students and organizations, it is necessary to manage funds scientifically, rationally plan the use of funds and conduct regular audits and self-examinations so as to avoid unreasonable use of funds for activities.

\section{ESTABLISH THE BIDIRECTIONAL ASSESSMENT MECHANISM}

The evaluation mechanism of the work of the vocational college is mostly adopted as a single mode, that is, the supervisors assess the subordinates and the teachers assess the students, and the evaluation of the functional institutions with guidance status is poor. If the evaluation of capacity, dedication and effectiveness of superior departments are added, the author believes that it will help to form joint efforts, competing atmosphere and will improve the working level. The suggestion is worth discussing.

\section{CONCLUSION}

In a word, it is a long-term project to carry out the thematic education activities at different levels in vocational colleges. The vocational college should not only combine the policy of the state, the characteristics of the students' age, but also the updates of modern educational methods and the development of the enterprise culture, thus constantly refreshing the educational pattern and keeping pace with the times. Moreover, the school should be good at uniting the forces of all parties, establish and constantly revise the relatively stable moral education system so as to facilitate the inheritance of generations of school management workers and precipitate the campus culture.

\section{REFERENCES}

[1] The successful experience of higher vocational education in France and its inspiration [J], Shen Zhiyang, Chen Xueli, Journal of Anqing Normal School(Social Science Edition), 201302.

[2] Analysis of the psychological situation of higher vocational students and countermeasures of ideological and political education [J], Zhao Lina, Northwest Medical Education, 200906.

[3] The sticking point between moral education and teaching in vocational colleges[J]. Kuang Ying, Journal of Jiangsu Normal School of Technology (Vocational Education Newsletter), 2009 (11).

[4] Strategies of how do secondary vocational class teachers infiltrate moral education in teaching [J], Wei Meiting, Modern vocational education, 2017 (23). 